\title{
FORMULATION AND IN-VITRO EVALUATION GASTRORETENTIVE DRUG DELIVERY OF TINIDAZOLE
}

\author{
Dalvi P. B. ${ }^{*}{ }^{1}$, Nandan S. S. ${ }^{1}$, Ingale P. R. ${ }^{2}$, Gangurde S. A. ${ }^{1 .}$ \\ ${ }^{1}$ Department of pharmaceutics, SND College Of Pharmacy, s Yeola, Nashik (MH), India \\ ${ }^{2}$ Women College Of Pharmacy, Chincholi , Nashik (MH), India \\ *Corresponding Author's Email: prashantdalvi26@gmail.com, sagarnandan5130@gmail.com
}

Received 12 Jan 2015; Review Completed 12 Feb 2015; Accepted 13 March 2015, Available online 15 March 2015

\begin{abstract}
ABSTACT
The aim of the current study was to design oral controlled release gastro-retentive drug delivery of Tinidazole. that are designed to retain in the stomach for a long time and have developed as a Local drug delivery system for better eradication of Helicobacter Pylori in peptic ulcer diseases. Tablets were prepared by direct compression and evaluated for evaluated for various physical parameters, Hardness, friability, drug Content, floating ability, Lag time, Swelling Index studies, and in vitro dissolution parameters as well as kinetics of release were assessed. Factorial design for 2 factors at 3 levels each was employed to systematically optimize drug release profile and Floating Behavior. Sodium Alginate and Hydroxy Propyl Metheyl Celluiose (HPMC K15M) were taken as the independent variables. Response surface plots and contour plots were drawn. Compressed tablets exhibited zero order drug release kinetics, resulting in regulated and complete release until 12 hours. Polynomial mathematical models, generated for various response variables using multiple linear regression analysis, were found to be statistically significant $(\mathrm{P}<0.05)$. Both the polymers had significant effect on the release profiles of the tablets, Besides unraveling the effect of the 2 factors on the various response variables, the study helped in finding the optimum Formulation 'F4' with Floating Lag Time (20 sec.) and having controlled release upto 12 hours $(99.47 \%)$. Meanwhile, sustained profiles of drug release were also obtained. In general, these systems can float in the gastric conditions and control the drug release from the tablets.
\end{abstract}

Keywords: Controlled release gastro-retentive drug delivery, Tinidazole, HPMC K15M

\section{INTRODUCTION}

Oral route is the most convenient and extensively used route for drug administration. Over the years the oral dosage forms have become sophisticated with development of controlled release drug delivery system (CRDDS). ${ }^{1}$

Oral delivery of drugs is one of the easiest route of drug delivery due to the ease of administration, patient compliance and flexibility in formulation etc. From immediate release to site specific delivery, oral dosage forms have really progressed. Gastroretentive dosage forms significantly extend the period of time, over which drug may be released and thus prolong dosing intervals and increase patient compliance. Such retention systems are important for those drug that are degraded in the intestine like antacids or certain antibiotics, enzymes that act locally in the stomach. This systems can be retained in the stomach and assist in improving the oral sustained delivery of drugs that have an absorption window in a particular region of the gastrointestinal tract, thus ensuring optimal bioavailability. ${ }^{2-3}$ The retentive characteristics of the dosage form are not significant for the drugs that: They Are insoluble in intestinal fluids Act locally to overcome these limitations, various approaches have (C) 2011-15, JDDT. All Rights Reserved been proposed to increase gastric residence of drug delivery systems in the upper part of the gastrointestinal tract includes floating drug dosage systems (FDDS) swelling or expanding systems, mucoadhesive systems , modified-shape systems, high-density system, and other delayed gastric emptying devices. Among these systems, FDDS have been most commonly used. ${ }^{4}$ During the early 1980s, Marshall and Warren first time isolated a spiral, urease producing, flagellate gramnegative bacterium that was later identified as Helicobacter pylori, a causative factor in the etiology of peptic ulcer disease. H. pylori appear to be responsible for $95 \%$ of the cases of gastritis and $65 \%$ of gastric ulcers. Although most individuals with $H$. pylori are asymptomatic, there is now convincing evidence that this bacterium is the major etiologic factor in chronic dyspepsia, H. pylori-positive duodenal and gastric ulcers and gastric malignancy. Consequently, H. pylori eradication is now recognized to be the correct approach along with conventional therapies in the treatment of the disease. Options that have been considered to treat peptic ulcer disease include taking drugs such as antacids, H- blockers (antihistaminics), antimuscarinics, proton pump inhibitors and 
combination therapy for gastritis associated with $H$. pylori. The bacterium is also considered a risk factor for the development of gastric adenocarcinoma and mucosa-associated lymphoid tissue (MALT) lymphoma.

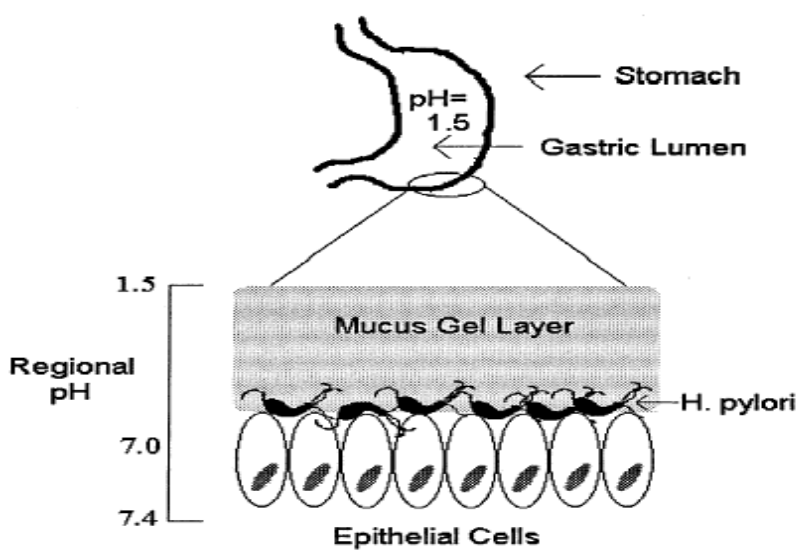

Figure 1: Schematics of $H$. pylori location within the stomach $^{5}$

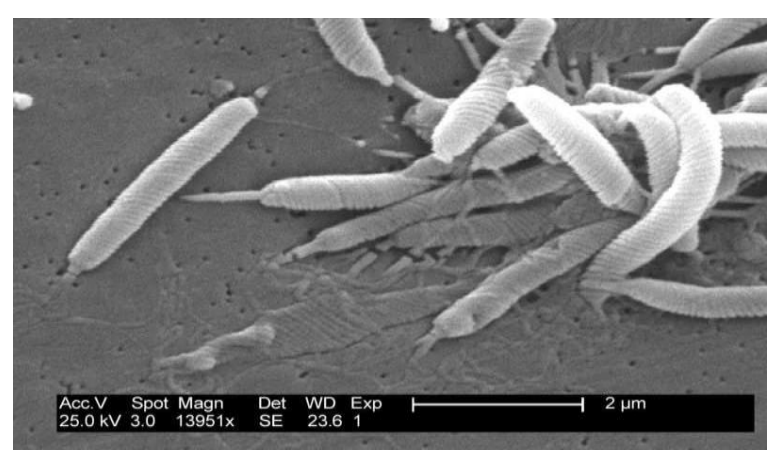

Figure 2: H.pylori photograph ${ }^{6}$

The eradication of $H$. pylori is limited by its unique characteristics. Once acquired, it penetrates the gastric mucus layer and fixes itself to various phospholipids and glycolipids on the epithelial surface. Therefore, the organism exclusively resides on the luminal surface of the gastric mucosa under the mucus gel layer in the acidic environment of the stomach as per Fig. 1

The bacteria is S-shaped, gram-negative, having flagella as shown in fig. 12 and measuring 0.5 to $1.0 \mathrm{~mm}$ in width and 2.5 to $4.0 \mathrm{~mm}$ in length.

For effective $H$. pylori eradication, therapeutic agents have to penetrate the gastric mucus layer to disrupt and inhibit the mechanism of colonization. This requires targeted drug delivery within the stomach environment. Although most antibiotics have very low in vitro minimum inhibitory concentrations (MIC) against $H$. pylori, no single antibiotic has been able to eradicate this organism effectively. Currently, a drug combination namely "triple therapy" with bismuth salt, Tinidazole and either drugs such as antacids, $\mathrm{H}$-blockers, antimuscarinics, tetracycline or amoxycillin with healing rates of up to $94 \%$ has been successfully used. The principle of triple therapy is to attack H. pylori luminally as well as systemically. The current treatment is based on frequent administration (4 times daily) of individual dosage forms of bismuth, tetracycline and Tinidazole (Helidac Therapy, consisting of $262.4 \mathrm{mg}$ bismuth subsalicylate, $500 \mathrm{mg}$ tetracycline and $250 \mathrm{mg}$ Tinidazole). The associated limitations are the complex dosing regimen/ frequency, large amount of doses and reduced patient compliance. Therefore, a successful therapy not only includes the selection of the right drugs but also the timing and frequency as well as the formulation of the delivery system.

Recently, gastroretentive systems for treating H.Pylori have shown special interest. The prolongation of the local availability of the antibacterial agents has been reported as an important factor to increase the effectiveness of H.pylori treatment. This will ensure a high concentration in the gastric mucosa for better microbial eradication. Stomach specific floating Tinidazole-loaded alginate beads were prepared and proved its superiority over Tinidazole suspension in local anti-H.pylori therapy.
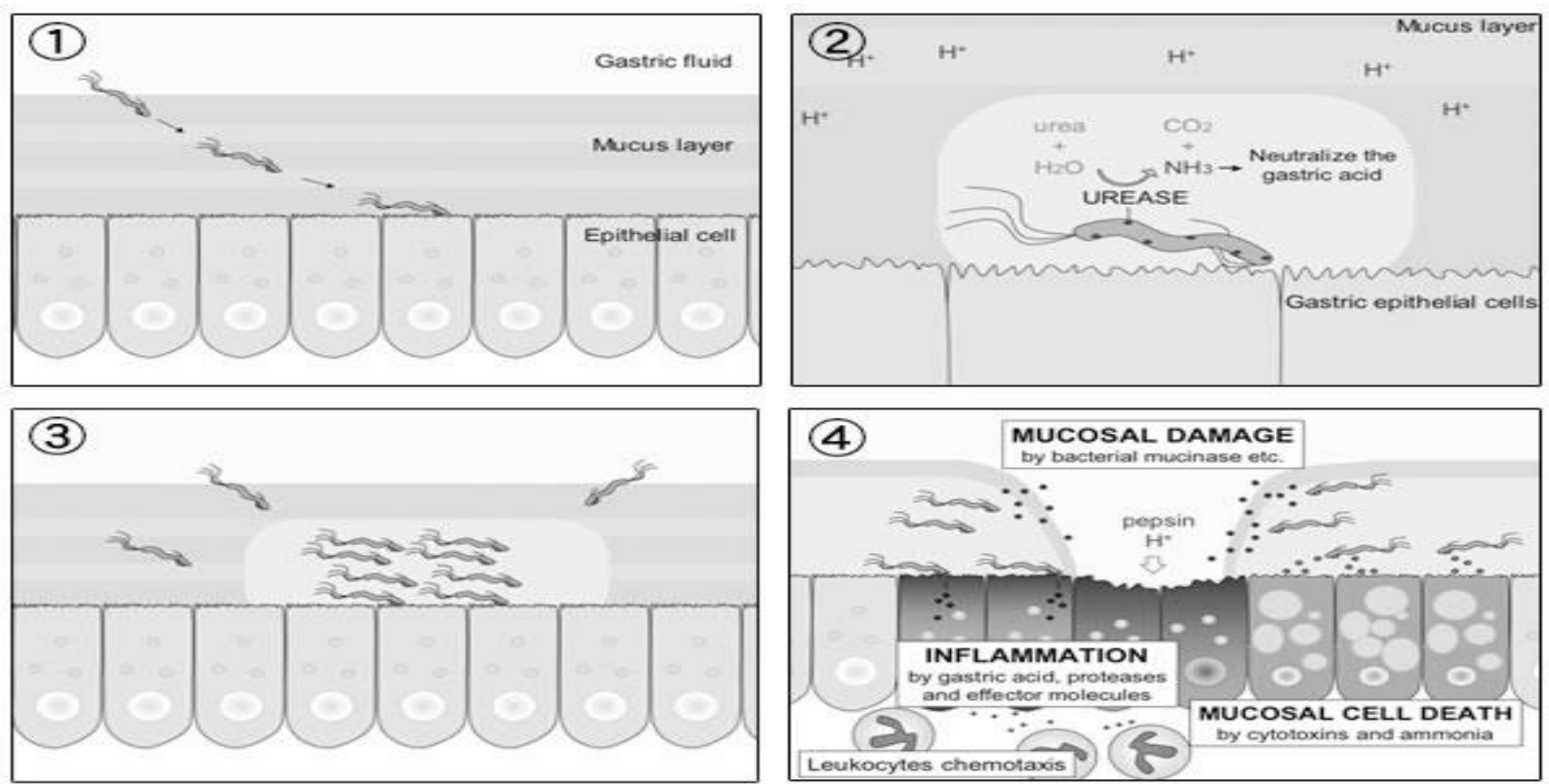

Figure 3: Mucosal damage caused by H.pylori ${ }^{\text {5-6 }}$ 
Tinidazole,1-[2-(ethylsulfonyl)ethyl]2-methyl-5nitroimidazole-1-ethanol, is a nitroimidazole derivative with activity against anaerobic protozoa, aerobic and microaerophilic bacteria. Common adverse effects of Tinidazole involve the gastrointestinal tract and the neurological system with high doses. Therefore, reduction of side effects of Tinidazole (plasma peak levels) while prolonging its action by using controlled oral dosage forms is highly desirable. Using various polymers can control drug release. The present study aimed to develop controlled release Floating Drug Delivery System (FDDS), which will remain in stomach for 12 hours while controlling drug release to achieve target release profile using a combination of Hydroxy Propyl Methyl Cellulose (HPMC $\mathrm{K}_{15} \mathrm{M}$ ) and Sodium Alginate as Polymer.

\section{MATERIALS AND METHODS}

Tinidazole was received as a gift sample from Aarti Drug Lab (Mumbai, India) Hydroxy propyl methylcellulose K- 15M (HPMC- K15M) was obtained from Colorcon Asia Pvt Ltd (Goa, India) and Microcrystalline cellulose was received as a gift sample from Colorcon Asia Pvt Ltd (Goa, India) . Sodium bicarbonate, citric acid, magnesium stearate, talc were purchased from Poona Chemicals Laboratories (Pune, India). All other chemicals were of analytical grades as required.

\section{Methods}

Effervescent Floating tablets containing Tinidazole were prepared by direct compression technique using varying concentrations of different grades of polymers with Sodium bicarbonate and citric acid. All the ingredients were accurately weighed and passed through different mesh sieves accordingly. Then, except Magnesium stearate all other ingredients were blended uniformly in glass mortar After sufficient mixing of drug as well as other components, Magnesium stearate was added, as post lubricant, and further mixed for additional 2-3 minutes. The tablets were compressed using rotary tablet machine. The weights of the tablets were kept constant for all formulation

\section{Experimental}

\section{Characterization of Tinidazole ${ }^{7}$}

Description: The sample of tinidazole was analyzed for its nature, color and taste.

Melting Point: The melting point was taken by open capillary method.

Standard Curve of Tinidazole: Tinidazole has been quantitatively analyzed by various techniques. In present studies, Tinidazole was estimated by UV Spectrophotometry method.

Infrared spectra analysis: ${ }^{8}$ Infrared spectrum of Tinidazole was determined on Fourier Transform Infrared Spectrophotometer (FTIR-4100s) using $\mathrm{KBr}$ dispersion method. The base line correction was done using dried potassium bromide. Then the spectrum of dried mixture of drug and potassium bromide was run.

Differential scanning calorimetry: DSC was performed in order to assess the thermotropic properties and thermal behavior of Tinidazole. About $5 \mathrm{mg}$ of the sample were sealed in the aluminum pans and heated at the rate of $10^{\circ} \mathrm{C} / \mathrm{min}$, covering a temperature range of $40^{\circ} \mathrm{C}$ to $300^{\circ} \mathrm{C}$ under nitrogen atmosphere of flow rate $100 \mathrm{ml} / \mathrm{min}$.

Ultraviolet (UV) spectroscopy: ${ }^{7} \mathrm{UV}$ spectrum of 25 $\mu \mathrm{g} / \mathrm{ml}$ solution of the drug powder in $0.1 \mathrm{~N}$ aqueous hydrochloric acid solution was recorded in the range of wavelengths from $200 \mathrm{~nm}$ to $400 \mathrm{~nm}$ using UV-visible Double beam Spectrophotometer (UV-Chemito-2600).

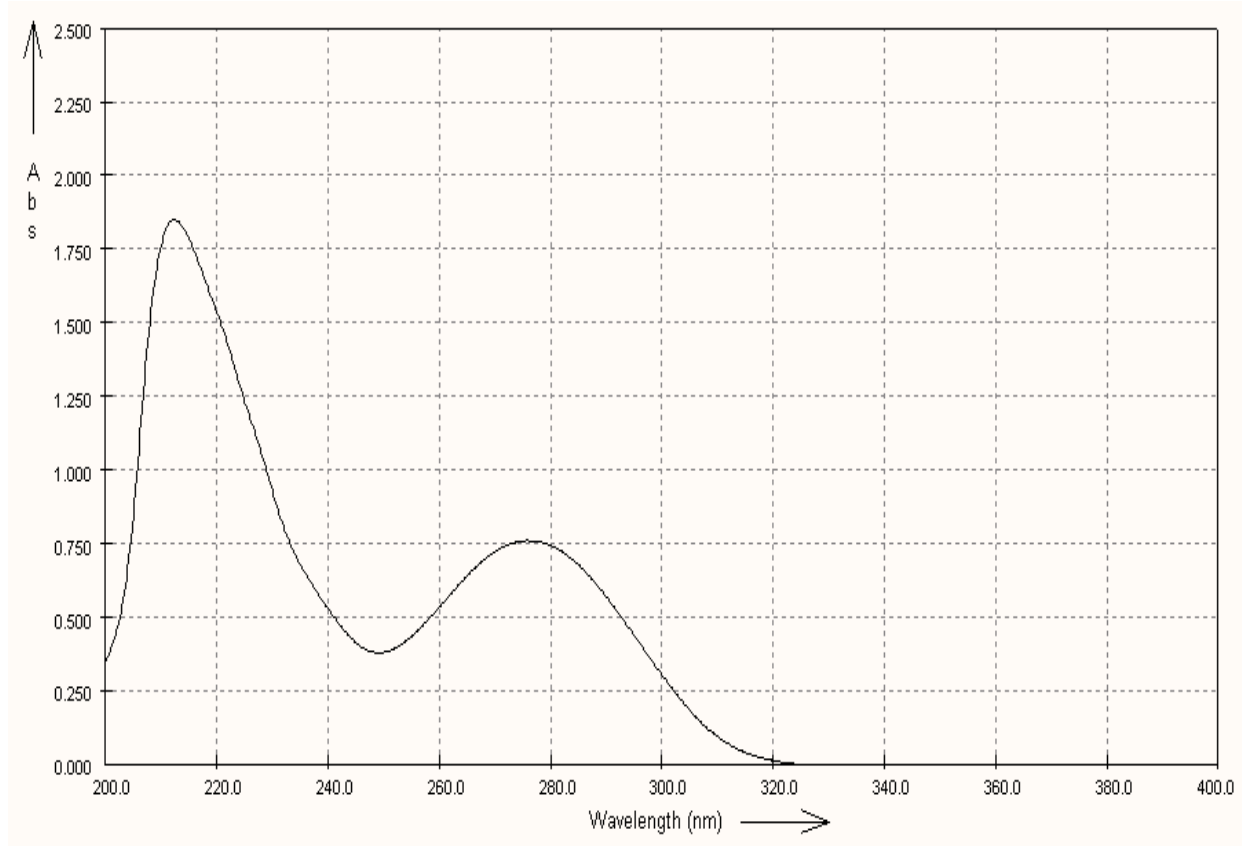

Figure 4: UV spectrum of Tinidazole in $0.1 \mathrm{~N}$ hydrochloric acid ( $\mathrm{HCl})$ 


\section{Preliminary formulations:}

Before selection of ratio of two polymers that is HPMC K15M and Sodium Alginate, low and high levels of independent variables should be fixed. This was achieved by preparation of some preliminary formulations.

Table 1: Formula for Preliminary Formulation:

\begin{tabular}{|c|c|c|c|c|}
\hline $\begin{array}{c}\text { Ingredient } \\
(\mathbf{m g})\end{array}$ & \multicolumn{4}{|c|}{ Formulation } \\
\cline { 2 - 5 } & $\mathbf{P}$ & $\mathbf{Q}$ & $\mathbf{R}$ & $\mathbf{S}$ \\
\hline Tinidazole & $\mathbf{3 0 0}$ & $\mathbf{3 0 0}$ & $\mathbf{3 0 0}$ & $\mathbf{3 0 0}$ \\
\hline Sodium Alginate & $\mathbf{5 0}$ & $\mathbf{1 0 0}$ & $\mathbf{1 5 0}$ & $\mathbf{2 0 0}$ \\
\hline HPMC K $_{\mathbf{1 5}} \mathbf{M}$ & $\mathbf{2 0 0}$ & $\mathbf{1 5 0}$ & $\mathbf{1 0 0}$ & $\mathbf{5 0}$ \\
\hline Total & $\mathbf{5 5 0}$ & $\mathbf{5 5 0}$ & $\mathbf{5 5 0}$ & $\mathbf{5 5 0}$ \\
\hline
\end{tabular}

\section{Full Factorial Design:}

Initially Sodium Alginate shows better swelling index than HPMC K15M at low concentration but at 12 hours HPMC K15M shows high swelling, However matrix erosion of HPMC K15M was higher than Sodium alginate at low Conc.as a result release of drug from HPMC K15M matrix will be higher at than required.
Hence lower levels of Sodium alginate and higher levels of HPMC K15M were selected for factorial design. Based on the results obtained with preliminary formulations, $3^{2}$ randomized full factorial designs were applied in the present study. In this design 2 factors will be evaluated, each at 3 levels, and experimental trials will be performed at all 9 possible combinations. The amount of polymer that is HPMC K15M and Sodium alginate was selected as independent variables. The Floating Lag Time, cumulative percent drug released in 1 \& 10 hrs (Q1 \& Q10) is selected as dependent variables. The probable formulations using $3^{2}$ randomized full factorial designs are as shown in the Table 3.

Table 2: Factor levels:

\begin{tabular}{|c|c|c|c|}
\hline Coded level & -1 & 0 & +1 \\
\hline HPMC K15M (X1) & 130 & 150 & 170 \\
\hline $\begin{array}{c}\text { Sodium Alginate } \\
\text { (X2) }\end{array}$ & 70 & 90 & 110 \\
\hline
\end{tabular}

So the possible combinations of two independent factors having three levels can be given as,

\begin{tabular}{|c|c|c|c|c|c|c|c|c|c|}
\hline $\begin{array}{c}\text { Independent } \\
\text { Variable }\end{array}$ & F1 & F2 & F3 & F4 & F5 & F6 & F7 & F8 & F9 \\
\hline X1 & -1 & -1 & -1 & 0 & 0 & 0 & $+!$ & +1 & +1 \\
\hline X2 & -1 & 0 & $+!$ & -1 & 0 & +1 & -1 & 0 & +1 \\
\hline
\end{tabular}

\section{Preparation of Floating Tablet of Tinidazole: ${ }^{8-9}$}

Floating tablets each containing $300 \mathrm{mg}$ of Tinidazole were prepared in different proportions of drug and polymer as per given in (Table 3). Different tablet formulations were prepared by direct compression method ${ }^{8,9}$. All the powders passed through Sieve No.
60. The required quantities of medicament and polymers were mixed thoroughly in a glass mortar by following geometric dilution technique. Then it was mixed with sodium bicarbonate and lubricated with magnesium stearate $(1 \% \mathrm{w} / \mathrm{w})$. Then the tablets were compressed in compression machine at specified pressure with $12 \mathrm{~mm}$ oval punch.

Table 3: Formulation of Tinidazole floating Tablet

\begin{tabular}{|c|c|c|c|c|c|c|c|c|c|}
\hline \multirow{2}{*}{$\begin{array}{c}\text { Ingredient } \\
\text { (mg) }\end{array}$} & \multicolumn{9}{|c|}{ Formulation } \\
\hline & F1 & F2 & $\mathbf{F 3}$ & F4 & F5 & F6 & F7 & F8 & F9 \\
\hline Tinidazole & 300 & 300 & 300 & 300 & 300 & 300 & 300 & 300 & 300 \\
\hline HPMC K ${ }_{15} M$ & 130 & 130 & 130 & 150 & 150 & 150 & 170 & 170 & 170 \\
\hline Sodium Alginate & 70 & 90 & 110 & 70 & 90 & 110 & 70 & 90 & 110 \\
\hline Sodium-bi carbonate & 70 & 70 & 70 & 70 & 70 & 70 & 70 & 70 & 70 \\
\hline $\begin{array}{l}\text { Microcrystalline } \\
\text { Cellulose }\end{array}$ & 125 & 95 & 75 & 95 & 75 & 55 & 75 & 55 & 35 \\
\hline Magnesium Stearate & 15 & 15 & 15 & 15 & 15 & 15 & 15 & 15 & 15 \\
\hline
\end{tabular}

\section{Evaluation of Tinidazole floating tablets}

Pre compression parameters ${ }^{10-11}$

The flow properties of powder blend (before compression) were characterized in terms of angle of repose, tapped density, bulk density, Carr's index and Hausner's ratio.

\section{Post compression parameters-}

i) Thickness and diameter 
Control of physical dimensions of the tablet such as thickness and diameter is essential for consumer acceptance and tablet uniformity ${ }^{\mathbf{1 2}}$. The thickness and diameter of the tablet was measured using vernier callipers. It is expressed in mm. Five tablets were used and average values were calculated.

\section{ii) Hardness}

It indicates the ability of a tablet to withstand mechanical shocks while handling. The hardness of the tablets was determined using Pfizer hardness tester. The value was noted in $\mathrm{kg} / \mathrm{cm} 2$. Three tablets were randomly picked and the hardness of the tablets was determined.

\section{iii) Weight variation}

Randomly selected twenty tablets were weighed individually and together in a single pan balance. The average weight was noted and standard deviation was calculated ${ }^{[13,14]}$. The tablet passes the test if not more than two tablets fall outside the percentage limit and none of the tablet differs by more than double percentage limit.

\section{$\%$ Deviation $=($ Wavg - Winitial $) /$ Wavg $\times 100$}

where, Wavg - average weight of tablet, Winital individual weight of tablet.

\section{iv) Friability}

Tablet strength was tested by Roche Friabilator. It is expressed in percentage $(\%)$. Ten tablets were initially weighed (W0) and into Friabilator ${ }^{[15] .}$ The Friabilator was operated at $25 \mathrm{rpm}$ for $4 \mathrm{~min}$ or run up to 100 revolutions. The tablets were weighed again $(\mathrm{W})$. The $\%$ friability was then calculated by:

$$
\% \text { Friability }=(\mathrm{W0}-\mathrm{W} / \mathrm{W0}) \times \mathbf{1 0 0}
$$

where, W0 - initial weight of tablets, W - final weight of tablets. \% Friability of tablets less than $1 \%$ are considered acceptable.

\section{v) In vitro buoyancy studies}

The in vitro buoyancy was determined by floating lag time method. The tablets were placed in $250 \mathrm{~mL}$ beaker containing $0.1 \mathrm{~N} \mathrm{HCl}{ }^{[16]}$. The time required for the tablets to rise to the surface and float was determined as floating lag time (FLT). The time between introduction of dosage form and its buoyancy in $0.1 \mathrm{~N} \mathrm{HCl}$ and the time during which the dosage form remain buoyant were measured. The total duration of time by which the dosage form remains buoyant is called total floating time (TFT).

\section{Swelling study}

Swelling of hydrophilic polymer such as Hydroxy Propyl Methyl Cellulose greatly depends upon the contents of the stomach and the osmolarity of the medium. These eventually influences the release, slowing action and the residence time. For each formulation, one tablet was weighed and placed in a beaker containing $200 \mathrm{ml}$ of distilled water. After each hour the tablet was removed from beaker and weighed again upto 8 hours. The percentage weight gain by the tablet was calculated by using the formula.

\section{Swelling index $($ S.I $)=\{($ Wt - Wo $) /$ Wo $\}$ x 100}

Where, S.I. = swelling index

$\mathrm{Wt}=\mathrm{Weight}$ of tablet at time $\mathrm{t}$

Wo $=$ Weight of tablet before immersion.

\section{In vitro drug release}

In vitro drug release of the samples was carried out using type-II dissolution apparatus (Paddle type). The dissolution medium, $900 \mathrm{~mL}$ of $0.1 \mathrm{~N} \mathrm{HCl}$ buffer was placed into the dissolution flask maintaining the temperature of $37 \pm 0.5^{\circ} \mathrm{C}$ and $50 \mathrm{rpm}{ }^{17}$. Tablet was placed in each vessel and operated the apparatus at 50 rpm for $12 \mathrm{~h}$. Withdrawn $5 \mathrm{~mL}$ of the sample solution from each vessel through $5 \mathrm{~mL}$ syringes after 1, 2, 4, 6, $8,10,12 \mathrm{~h}$ and replaced with equal volume of fresh dissolution medium previously equilibrated to $37 \pm$ $0.5^{\circ} \mathrm{C}$. Each sample was filtered through $0.45 \mu \mathrm{m}$ filter and collected in separate vials. The samples were analyzed by UV. The percentage drug released at different time points were calculated. The cumulative percentage drug release vs time profiles of different formulations were Plote. The release data were analyzed as per Zero order, First order, Higuchi's and Peppas equation models 18.

\section{Data analysis: ${ }^{19-22}$}

To analyze the mechanism of release and release rate kinetics of the dosage form, the data obtained were fitted into Zero order, First order, Higuchi matrix, Peppas and Hixson Crowell model using PCP-DISSO v3 software.

\section{RESULTS AND DISCUSSION}

\section{Pre compression parameters}

All the pre-compressional parameters like bulk density, tapped density, angle of repose, Carr's index, Hausner's ratio etc were evaluated and were found to be within the limits, indicating the power blend has the required flow property for compression. The tablets were prepared by direct compression method. In the Preformulation studies, compatibility studies were performed using FTIR spectrophotometer. The FTIR spectrum of pure drug and physical mixture of drug and polymer were studied. The peaks obtained in the spectra's of each formulation correlated with the peaks of pure drug spectrum. So it was concluded that no significant difference in peak pattern in IR spectrum of drug, polymer and the excipients exists. The values obtained for the preformulation parameters for the formulations F1 to F9 are tabulated in Table 4. 
Table 4: Pre-compression evaluation of Tinidazole floating tablets

\begin{tabular}{|c|c|c|c|c|c|}
\hline $\begin{array}{l}\text { Formulation } \\
\text { Code }\end{array}$ & $\begin{array}{c}\text { Angle of Repose }\left(^{\circ}\right) \\
\mathbf{\pm} \mathbf{S D}^{*}\end{array}$ & $\begin{array}{c}L B D\left(\mathrm{gm} / \mathrm{cm}^{2}\right) \\
\mathbf{\pm} \mathbf{S D}^{*}\end{array}$ & $\begin{array}{c}T B D\left(\mathrm{gm} / \mathrm{cm}^{2}\right) \\
\mathbf{\pm \text { SD } ^ { * }}\end{array}$ & $\begin{array}{c}\text { Compressibility index } \\
(\boldsymbol{\%}) \pm \text { SD }^{*}\end{array}$ & $\begin{array}{c}\text { Hausner's ratio } \\
\mathbf{\pm} \mathbf{S D}^{*}\end{array}$ \\
\hline F1 & $35.53 \pm 0.45$ & $0.375 \pm 0.006$ & $0.479 \pm 0.025$ & $21.42 \pm 4.47$ & $1.27 \pm 0.07$ \\
\hline F2 & $36.76 \pm 0.55$ & $0.387 \pm .005$ & $0.506 \pm 0.005$ & $23.54 \pm 1.76$ & $1.30 \pm 0.03$ \\
\hline F3 & $37.13 \pm 0.32$ & $0.394 \pm .009$ & $0.504 \pm 0.007$ & $21.75 \pm 0.62$ & $1.27 \pm 0.01$ \\
\hline F4 & $35.13 \pm 0.40$ & $0.349 \pm 0.005$ & $0.456 \pm 0.004$ & $21.44 \pm 0.81$ & $1.30 \pm 0.01$ \\
\hline F5 & $36 \pm 0.26$ & $0.366 \pm 0.004$ & $0.482 \pm 0.004$ & $23.98 \pm 1.69$ & $1.31 \pm 0.02$ \\
\hline F6 & $36.53 \pm 0.45$ & $0.375 \pm 0.004$ & $0.482 \pm 0.026$ & $21.97 \pm 4.32$ & $1.28 \pm 0.06$ \\
\hline F7 & $33.3 \pm 0.81$ & $0.338 \pm 0.002$ & $0.440 \pm 0.001$ & $23.23 \pm 0.44$ & $1.30 \pm 0.007$ \\
\hline F8 & $34.5 \pm 0.7$ & $0.337 \pm 0.003$ & $0.458 \pm 0.003$ & $26.41 \pm 0.38$ & $1.35 \pm 0.007$ \\
\hline F9 & $35.13 \pm 0.25$ & $0.353 \pm 0.005$ & $0.470 \pm 0.002$ & $24.92 \pm 1.42$ & $1.33 \pm 0.02$ \\
\hline
\end{tabular}

* All values are mean $\pm S D,(n=3)$.

\section{Post compression parameters}

Hardness of the tablet was in the range 5.21 \pm 0.1 to $5.37 \pm 0.24 \mathrm{~kg} / \mathrm{cm} 2$. Weight loss in the friability test was in the range $0.24 \pm 0.01$ to $0.62 \pm 0.02 \%$ (Table 5). All the floating tablets prepared contained Tinidazole within the range of $100 \pm 4 \%$ of the labeled claim.

Table 5: Post-compression evaluation of Tinidazole floating tablets

\begin{tabular}{|c|c|c|c|c|c|}
\hline \multirow[t]{2}{*}{ Formulation code } & \multicolumn{5}{|c|}{ Evaluation parameter } \\
\hline & $\begin{array}{c}\text { Thickness* } \pm \\
\text { S.D. }(\mathbf{m m}) \\
(\mathbf{n}=5)\end{array}$ & $\begin{array}{l}\text { Hardness* } \pm \\
\text { S.D. }\left(\mathbf{k g} / \mathbf{c m}^{2}\right) \\
(\mathbf{n}=\mathbf{5})\end{array}$ & $\begin{array}{c}\text { Friability } \\
(\%)\end{array}$ & $\begin{array}{c}\text { Average weight } \\
\text { variation€ } \\
(n=10)\end{array}$ & $\begin{array}{c}\text { Drug content* } \\
(\%)\end{array}$ \\
\hline F1 & $3.21 \pm 0.01$ & $5.22 \pm 0.03$ & $0.47 \pm 0.005$ & $697.3 \pm 0.35$ & $99.85 \pm 0.60$ \\
\hline F2 & $3.16 \pm 0.06$ & $5.23 \pm 0.02$ & $0.24 \pm 0.01$ & $695.6 \pm 0.27$ & $99.3 \pm 0.57$ \\
\hline F3 & $3.24 \pm 0.04$ & $5.35 \pm 0.03$ & $0.27 \pm 0.03$ & $695.0 \pm 0.75$ & $98.7 \pm 0.98$ \\
\hline F4 & $3.16 \pm 0.04$ & $5.21 \pm 0.03$ & $0.26 \pm 0.015$ & $698.1 \pm 1.02$ & $99.9 \pm 0.57$ \\
\hline F5 & $3.26 \pm 0.06$ & $5.32 \pm 0.02$ & $0.36 \pm 0.03$ & $695.2 \pm 0.39$ & $99.1 \pm 0.65$ \\
\hline F6 & $3.18 \pm 0.07$ & $5.37 \pm 0.02$ & $0.46 \pm 0.03$ & $697.2 \pm 0.37$ & $98.0 \pm 0.98$ \\
\hline F7 & $3.26 \pm 0.08$ & $5.21 \pm 0.02$ & $0.62 \pm 0.02$ & $692.0 \pm 0.71$ & $99.8 \pm 0.99$ \\
\hline F8 & $3.22 \pm 0.05$ & $5.23 \pm 0.01$ & $0.52 \pm 0.03$ & $697.8 \pm 0.6$ & $98.2 \pm 0.95$ \\
\hline F9 & $3.28 \pm 0.07$ & $5.28 \pm 0.01$ & $0.48 \pm 0.03$ & $695.4 \pm 0.39$ & $98.0 \pm 0.98$ \\
\hline
\end{tabular}

\section{In vitro buoyancy studies}

Buoyancy studies were performed using $0.1 \mathrm{~N} \mathrm{HCl}$ solution $\mathrm{pH} 1.2$ buffer at $37^{\circ} \mathrm{C}$ (Table 4); the tablets floated and remained without disintegration.

Table 6: In vitro buoyancy studies of Tinidazole

\begin{tabular}{|c|c|c|}
\hline $\begin{array}{c}\text { Formulation } \\
\text { code }\end{array}$ & $\begin{array}{c}\text { Floating lag time } \\
\text { (sec) }\end{array}$ & $\begin{array}{c}\text { Total floating } \\
\text { duration } \\
\text { ( hours) }\end{array}$ \\
\hline F1 & 16 & 12 \\
\hline F2 & 19 & 12 \\
\hline F3 & 23 & 12 \\
\hline F4 & 20 & 12 \\
\hline F5 & 24 & 12 \\
\hline F6 & 30 & 12 \\
\hline F7 & 28 & $12+\mathrm{B}$ \\
\hline F8 & 36 & 12 \\
\hline F9 & 42 & \\
\hline
\end{tabular}

\section{B-Brust}

\section{Swelling study}

Swelling study was performed for all the formulations F1- F9 for 12h (Table 7). Swelling increases as the time passes because the polymer gradually absorbs water due to hydrophilicity of polymer.

Table 7: Swelling Index of Tinidazole

\begin{tabular}{|c|c|c|c|}
\hline \multirow{2}{*}{ Formulation code } & \multicolumn{3}{|c|}{$\begin{array}{c}\text { Percent hydration or } \\
\text { swelling index In hours }\end{array}$} \\
\cline { 2 - 4 } & $\mathbf{4}$ & $\mathbf{8}$ & $\mathbf{1 2}$ \\
\hline F1 & 12 & 28 & 42 \\
\hline F2 & 42 & 63 & 79 \\
\hline F3 & 54 & 73 & 84 \\
\hline F4 & 22 & 38 & 52 \\
\hline F5 & 52 & 63 & 79 \\
\hline F6 & 61 & 78 & 86 \\
\hline F7 & 27 & 43 & 55 \\
\hline F8 & 52 & 63 & 80 \\
\hline F9 & 61 & 78 & 89 \\
\hline
\end{tabular}


Swelling index of blended formulation depicts the swellable nature of HPMC K15M and Sodium Alginate as shown in Table no 7. Both the polymers are hydrophilic in nature. As the concentration of polymers increases, swelling index also increase. On comparison of swelling index of formulation F1, F2 and F3, all contains equal amount of HPMC K15M, swelling index increases from F1 to F2 which indicates that swelling index depends on concentration of Sodium Alginate, increase the concentration of Sodium Alginate more will be swelling, higher the retardation of drug release. Same pattern was observed in case of Formulation F4, F5, F6 and in case of F7, F8, F9. In case of Formulation $\mathrm{F} 1, \mathrm{~F} 4$ and F7, as the concentration of HPMC K15M increased, matrix erosion was found to be increased.

\section{In vitro drug release}

Preliminary formulation:

Table 8: Drug release profile for Preliminary formulations:

\begin{tabular}{|c|c|c|c|c|c|c|c|}
\hline \multirow{2}{*}{$\begin{array}{c}\text { Formulation } \\
\text { Code }\end{array}$} & \multicolumn{7}{|c|}{ Percent drug release at time $\quad(h r)$} \\
\hline & 1 & 2 & 4 & 6 & 8 & 10 & 12 \\
\hline $\mathbf{P}$ & 48.03 & 56.80 & 61.117 & 69.543 & 83.267 & 96.064 & 97.506 \\
\hline $\mathbf{Q}$ & 46.027 & 54.955 & 60.345 & 65.681 & 77.8 & 93.819 & 95.165 \\
\hline $\mathbf{R}$ & 43.107 & 51.269 & 57.640 & 62.294 & 72.976 & 89.553 & 93.378 \\
\hline $\mathbf{S}$ & 39.855 & 49.583 & 55.945 & 63.508 & 67.776 & 84.408 & 88.288 \\
\hline
\end{tabular}

From the in-vitro results it was observed that as the concentration of Sod. Alginate increases, the release rate of Tinidazole from the formulations reduces which indicates release retardant nature of Sod. Alginate as shown in Table 8.

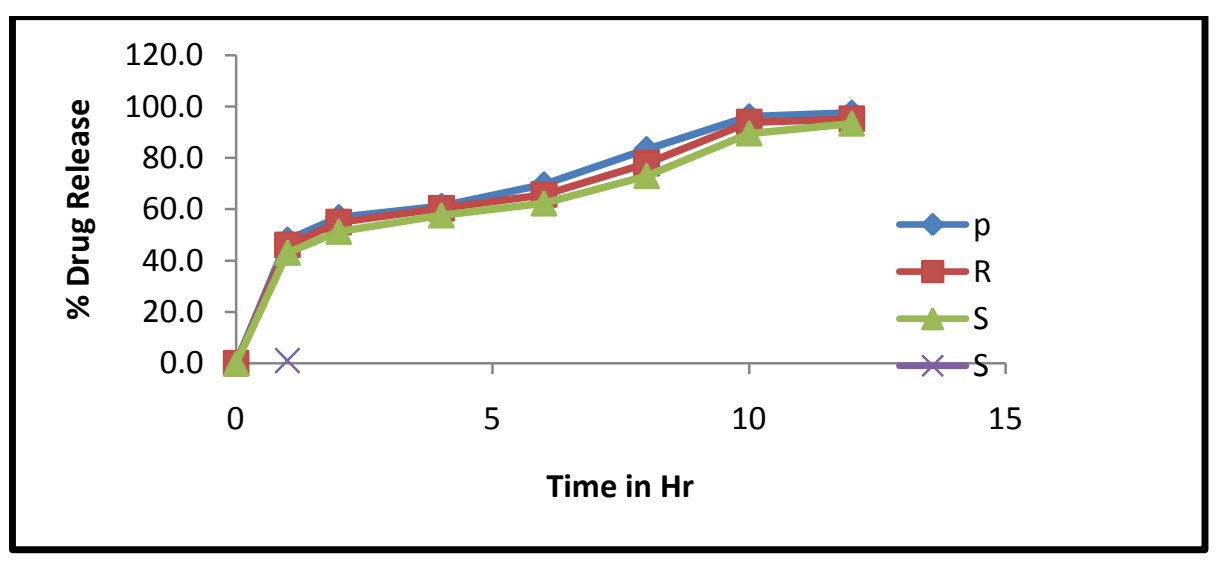

Figure 5: In vitro drug release from preliminary formulation

Table 9: In vitro drug release from blended formulation:

\begin{tabular}{|c|c|c|c|c|c|c|c|}
\hline \multirow{2}{*}{$\begin{array}{c}\text { Formulation } \\
\text { Code }\end{array}$} & \multicolumn{7}{|c|}{ Percent drug release at time $(\mathrm{hr})$} \\
\hline & 1 & 2 & 4 & 6 & 8 & $\mathbf{1 0}$ & 12 \\
\hline F1 & $54.78 \pm 0.912$ & $60.63 \pm 0.132$ & $68.05 \pm 0.32$ & $79.10 \pm 0.478$ & $80.52 \pm 0.296$ & $99.63 \pm 0.461$ & \\
\hline F2 & $49.26 \pm 0.356$ & $59.36 \pm 0.204$ & $63.47 \pm 0.163$ & $70.42 \pm 0.530$ & $84.15 \pm 0.174$ & $93.89 \pm 0.293$ & $97.26 \pm 0.352$ \\
\hline F3 & $45.15 \pm 0.302$ & $51.31 \pm 0.106$ & $58.57 \pm 0.305$ & $65.05 \pm 0.405$ & $75.15 \pm 0.540$ & $88.15 \pm 0.603$ & $94.89 \pm 0.305$ \\
\hline F4 & $46.00 \pm 0.294$ & $50.36 \pm 0.100$ & $60.94 \pm 0.203$ & $66.47 \pm 0.100$ & $79.10 \pm 0.192$ & $91.10 \pm 0.109$ & $99.47 \pm 0.402$ \\
\hline F5 & $44.36 \pm 0.501$ & $49.10 \pm 0.329$ & $58.57 \pm 0.345$ & $66.47 \pm 0.113$ & $75.94 \pm 0.183$ & $88.73 \pm 0.293$ & $97.42 \pm 0.304$ \\
\hline F6 & $43.15 \pm 0.4983$ & $49.10 \pm 0.492$ & $57.15 \pm 0.941$ & $64.89 \pm 0.132$ & $74.21 \pm 0.305$ & $84.47 \pm 0.309$ & $93.78 \pm 0.394$ \\
\hline F7 & $44.84 \pm 0.192$ & $50.56 \pm 0.529$ & $60.63 \pm 0.183$ & $68.94 \pm 0.193$ & $79.42 \pm 0.427$ & $90.15 \pm 0.509$ & $98.05 \pm 0.509$ \\
\hline F8 & $40.42 \pm 0.329$ & $44.84 \pm 0.592$ & $57.18 \pm 0.192$ & $64.10 \pm 0.429$ & $73.19 \pm 0.539$ & $86.21 \pm 0.513$ & $94.42 \pm 0.209$ \\
\hline F9 & $34.10 \pm 0.310$ & $40.73 \pm 0.309$ & $50.68 \pm 0.391$ & $57.78 \pm 0.451$ & $68.46 \pm 0.419$ & $80.68 \pm 0.319$ & $87.31 \pm 0.209$ \\
\hline $\begin{array}{c}\text { Theoratical } \\
\text { Drug } \\
\text { Release }\end{array}$ & 47.60 & 52.29 & 61.68 & 66.91 & 80.45 & 91.24 & 99.22 \\
\hline
\end{tabular}

Drug release from Formulation F1 was found $99.63 \pm$ 4.610 at 10 hours. This was attributed to fact that formulation F1 contains $70 \mathrm{mg}$ of Sodium Alginate. Formulation F2 and F3 showed drug release slower than
F1 because both contains $90 \mathrm{mg}$ and $110 \mathrm{mg}$ of Sodium Alginate respectively as shown in Fig .Concentration of HPMC K15M was equal in all three formulations. So Sodium Alginate retards the release of drug from 
formulation. Results of drug release from Formulation F4, F5, F6 and formulation F7, F8, F9 follows same pattern as of F1, F2 and F3. Percent drug release was important factor in optimization of gastroretentive drug delivery of Tinidazole.

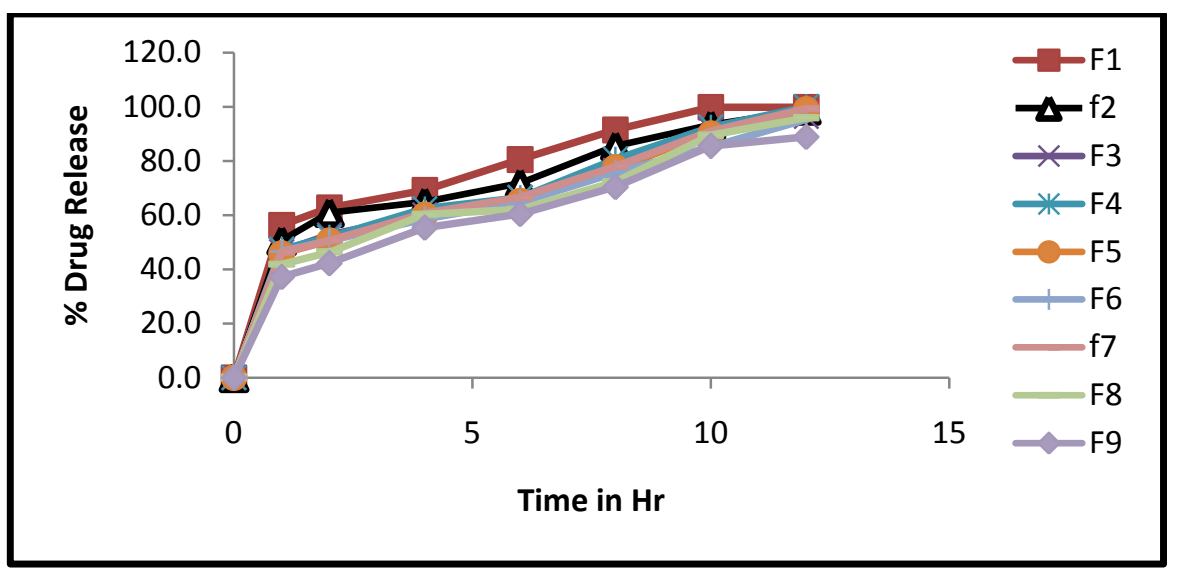

Figure 6: Comparative In Vitro release profile of F1 - F9 Formulation

\section{Release kinetics}

The release data were analyzed as per Zero order, First order, Higuchi's and Peppas equation models to know the pattern of drug release and mechanism of drug release from the Floating tablets.

Table 10: Drug release kinetics of blended formulations:

\begin{tabular}{|c|c|c|c|c|c|c|}
\hline Formulation code & \multicolumn{9}{|c|}{$\mathbf{R}^{2}$ values } \\
\hline & Zero order & First order & Higuchi & $\begin{array}{c}\text { Hixon- } \\
\text { crowell }\end{array}$ & $\begin{array}{c}\text { Korsmey- } \\
\text { Peppas }\end{array}$ & $\begin{array}{c}\text { n } \\
\text { n }\end{array}$ \\
\hline F1 & 0.8633 & 0.9090 & 0.9612 & 0.4299 & $\mathbf{0 . 9 7 7 8}$ & $\mathbf{0 . 4 9 3}$ \\
\hline F2 & 0.8825 & 0.9346 & 0.9665 & 0.4438 & $\mathbf{0 . 9 8 0 7}$ & $\mathbf{0 . 5 2 8}$ \\
\hline F3 & 0.7052 & 0.9500 & 0.9638 & 0.4687 & $\mathbf{0 . 9 9 0 6}$ & $\mathbf{0 . 5 3 8}$ \\
\hline F4 & 0.8696 & 0.9364 & 0.9648 & 0.4299 & $\mathbf{0 . 9 9 3 5}$ & $\mathbf{0 . 5 4 9}$ \\
\hline F5 & 0.8815 & 0.9539 & 0.9667 & 0.4438 & $\mathbf{0 . 9 9 6 4}$ & $\mathbf{0 . 6 0 7}$ \\
\hline F6 & 0.9034 & 0.9563 & 0.9697 & 0.4668 & $\mathbf{0 . 9 9 3 8}$ & $\mathbf{0 . 5 7 5}$ \\
\hline F7 & 0.9122 & 0.9050 & 0.9772 & 0.4299 & $\mathbf{0 . 9 9 6 3}$ & $\mathbf{0 . 6 0 4}$ \\
\hline F8 & 0.9161 & 0.9658 & 0.9797 & 0.4438 & $\mathbf{0 . 9 8 4 5}$ & $\mathbf{0 . 5 3 3}$ \\
\hline F9 & 0.9291 & 0.9769 & 0.9867 & 0.4668 & $\mathbf{0 . 9 9 2 0}$ & $\mathbf{0 . 5 4 5}$ \\
\hline
\end{tabular}

\section{Optimization:}

Table 11: Optimization Table with response variables:

\begin{tabular}{|c|c|c|c|c|c|}
\hline \multirow[t]{2}{*}{ Run } & \multirow{2}{*}{$\begin{array}{l}\text { HPMC } \\
\text { K15M }\end{array}$} & \multirow{2}{*}{$\begin{array}{l}\text { Sodium } \\
\text { Alginate }\end{array}$} & \multicolumn{2}{|c|}{ Percent drug release } & \multirow{2}{*}{$\begin{array}{l}\text { Floating } \\
\text { lag time }\end{array}$} \\
\hline & & & $\mathbf{Q}_{1 \mathrm{Hr}}$ & $Q_{10 \mathrm{Hr}}$. & \\
\hline 1 & +1 & 0 & 40.22 & 86.01 & 34 \\
\hline 2 & -1 & 0 & 49.00 & 93.70 & 18 \\
\hline 3 & 0 & +1 & 42.98 & 84.30 & 28 \\
\hline 4 & 0 & -1 & 45.80 & 91.06 & 18 \\
\hline 5 & -1 & -1 & 54.60 & 99.50 & 14 \\
\hline 6 & +1 & +1 & 34.03 & 80.50 & 40 \\
\hline 7 & -1 & +1 & 44.95 & 88.05 & 22 \\
\hline 8 & +1 & -1 & 44.82 & 90.03 & 26 \\
\hline 9 & 0 & 0 & 44.22 & 88.50 & 22 \\
\hline 10 & 0 & 0 & 44.52 & 88.96 & 26 \\
\hline 11 & +1 & -1 & 44.86 & 90.27 & 30 \\
\hline 12 & -1 & 0 & 49.52 & 94.08 & 20 \\
\hline 13 & 0 & -1 & 46.20 & 91.14 & 22 \\
\hline 14 & -1 & -1 & 54.96 & 99.76 & 18 \\
\hline 15 & -1 & +1 & 45.20 & 88.25 & 24 \\
\hline 16 & +1 & +1 & 34.17 & 80.86 & 44 \\
\hline 17 & +1 & 0 & 40.62 & 86.41 & 38 \\
\hline 18 & 0 & +1 & 43.17 & 84.64 & 32 \\
\hline
\end{tabular}


Total amount of tinidazole released from all the formulations until 12 hours ranged between $99.99 \%$ to $88.78 \%$ indicating almost complete drug release from all the formulations. Rate of percent drug release tended to decrease with increase in the content of either HPMC $\mathrm{K} 15 \mathrm{M}$ or Sodium Alginate. This in agreement with literature findings that the viscosity of gel layer around the Tablet increases with increase in the hydrogel concentration,thus limiting the release of active ingredient. Although they are described as 'soluble', During swelling state electrostatic repulsion between the negatively charged carboxyl groups cause uncoiling and gel formation. The gel, thus formed, consists of closely packed swollen particles. With further increase in polymer amount, thicker gel forms inhibiting water penetration more strongly,resulting in significant reduction in the values of perecent drug release at 12 hours.

\section{Factorial models and Response surface analysis}

i) Response surface plots for measured responses. $Q$ $\operatorname{lhr}\left(\mathrm{Y}_{1}\right)$

Three-dimensional response surface plots are presented in Figure 7 shows that cumulative drug release increases with decrease in concentrations of polymer. The Contour plots showing the effect of polymer concentration on the $\mathrm{Y}_{1}$ (cumulative drug release at 1 hr) is shown in Figure 7
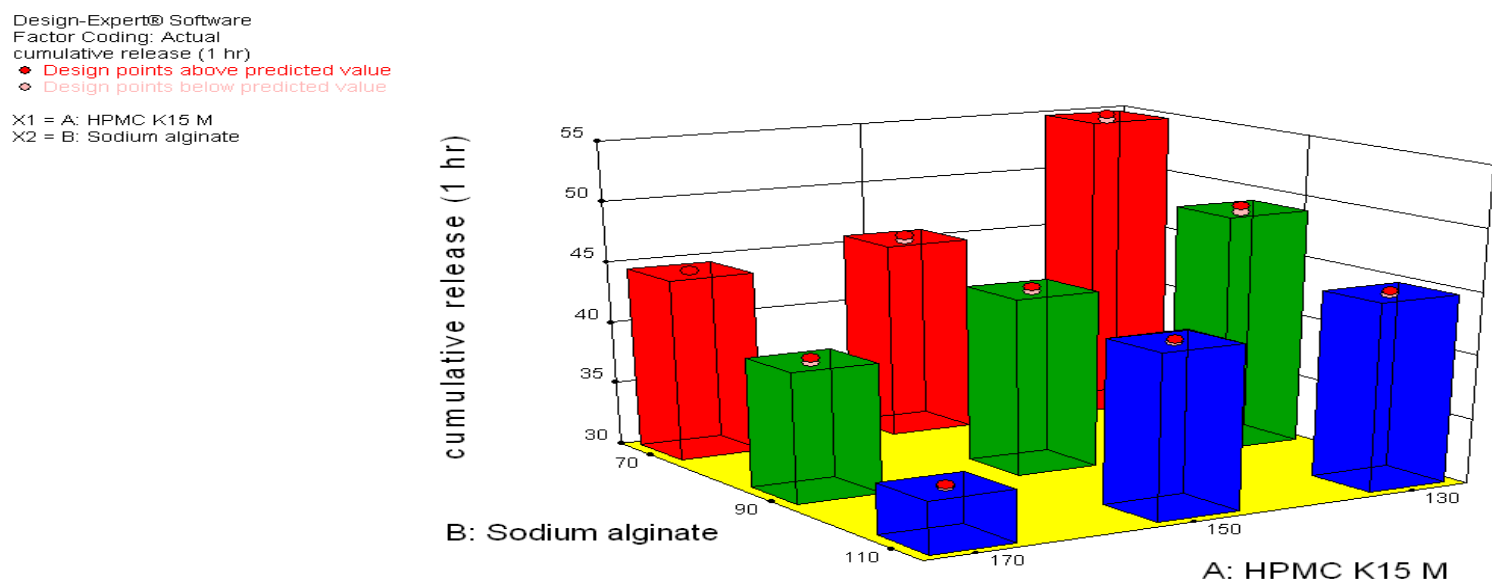

Figure 7: Response surface plot of cumulative percent drug release at 1 hours and levels of HPMC K15M and Sodium Alginate.

ii) Response surface plots for measured responses. $Q 10 \mathrm{hr}\left(\mathrm{Y}_{2}\right)$
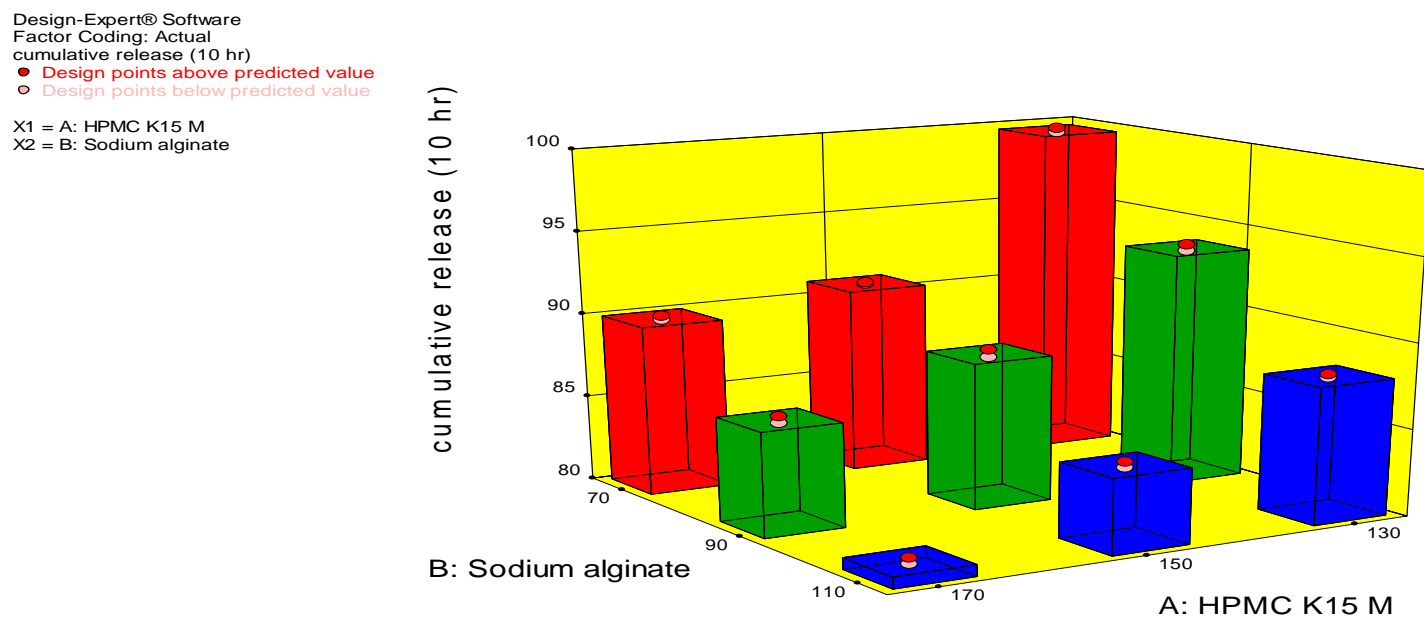

Figure 8: Response surface plot of cumulative percent drug release at 10 hours and levels of HPMC K15M and Sodium Alginate. 

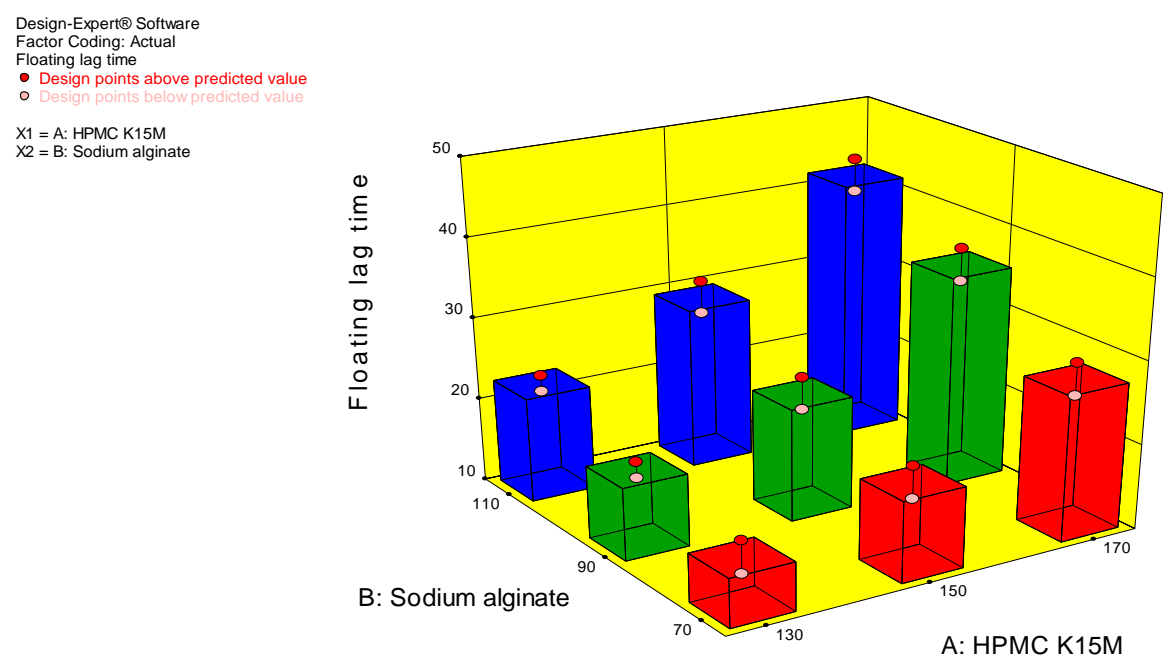

Figure 9: Response surface plot of Floating lag time and levels of HPMC K15M and Sodium Alginate.

Three-dimensional response surface plots are presented in Figure 9 shows that Floating lag time increases with increases in concentrations of HPMC K15M and Sodium alginate. Therefore it can be derived that the change in concentration of polymer had significant effect on the Floating lag time of the formulation.

\section{CONCLUSION:}

Regulated drug release in zero-order manner attained in the current study indicates that the optimized gastro-retentive tablet of Tinidazole, prepared using Sodium Alginate and HPMC K15M can successfully be employed as a oral controlled release drug delivery system. High Floating

\section{REFERENCES}

1. Jain NK. Gastroretentive drug delivery systems, In: Progress in controlled and novel drug delivery system. CBS Publishers and Distributors, New Delhi. 2004; Ist Edn: 76-97.

2. Rouge N, Buri P, Deolkar E, Drug absorption sites in the gastrointestinal tract and dosage forms for site specific drug delivery system, Int. J. Pharm., 1996; 136: 117- 139.

3. Alexander S, Juergen S. Gastroretentive drug delivery systems. Expert Opin. Drug Deliv. 2006; 3:217 233.

4. Rouge N, Buri P and Doelker E. "Drug absorption sites in the gastrointestinal tract and dosage forms for site specific delivery", International journal of pharmaceutics. 1996, 36, pp 117-139.

5. Goddard AF. Dignostic methods for Helicobactor pylori detection and eradication. J. Clin Pharmacol, 56, 273-293.

6. Erah PO, Goddard AF, Barret DA, Shaw PN, Spiller RC. The stability of amoxicillin, clarithromycin and metronidazole in gastric juice: relevance to the treatment of Helicobacter pylori infection. J Antimicrobial Chemotherapy, 39, 5-12.

7. Indian Pharmacopoeia 2007, Vol. 1, The Indian Pharmacopoeia Commission, Ghaziabad, Govt. of India, Ministry of Healthcare and Family Welfare, 162, 413, 1811,1185 .

8. Berner et al. United States Patent Application Publication US 201210027823 A1.

9. Narayana Charyulu, R., Patil, A.B., Lakshmi Deepika, C.H., Prabhakar Prabhu, Shastry, C.S., NUJHS 2011, 1, 38-45.

10. Patel Geeta, M., Patel Dinesh, H., International Journal of PharmTech Research 2010, 2, 1870-1882.

11. Rajalakshmi, G., Vamsi, C.H., Balachandar, R., Damodharan, N., Int J Pharm Biomed Res 2011, 2, 237-243. ability of the formulation is likely to increase its GI residence time, and eventually, improve the extent of bioavailability. However, appropriate balancing between various levels of the two polymers is imperative to acquire proper controlled release and byouncy. $3^{2}$ factorial design is quite efficient in optimizing gastro-retentive drug delivery system of Tinidazole. Floating tablet of Tinidazole can be successfully employed for eradication of H.pylori infection which is main cause of gastric ulcers. Gastroretentive dosage form of Tinidazole will reduce the frequency of administration of drug and helps to minimize dose of drug and side effects associated with the drug.
12. Chowdary, K.P.R., Areefulla Hussainy, S., Asian Journal of Pharmaceutical and Health Sciences 2012, 2, 316-319.

13. Sreenivasa Rao, K., Vairagkar, R.R., Udgirkar, D.B., Patil, P.S., Biradar, K.V., International Journal of Research in Pharmacy and Chemistry 2012, 2, 46-53.

14. Lachman., Liebermann, H.A., Kanig, J.L., The Theory and Practice of Industrial Pharmacy, 3rd Edn., Varghese Publishing House, Mumbai, 1991.

15. Neha Narang, Int J App Pharm 2011, 3, 1-7.

16. Makwana Ami, Sameja Krunal. Journal of Drug Delivery and Therapeutics 2012, 2, 12-21.

17. United States Pharmacopoeia, 25th Edn., The United States Pharmacopoeial Convention, Inc., Rockville, 2002, pp.18211824.

18. Cherng-ju Kim. Advance Pharmaceutics. Physicochemical Principles, CRC Press LLC 2004.

19. Chaturvedi K, Umadevi S, Vaghani S. Floating Matrix Dosage Form for Propranolol Hydrochloride Based on Gas Formation Technique: Development and In Vitro Evaluation. Sci Pharm. 2010; 78(4):927-939.

20. Havaldar VD, Kulkarni AS, Dias RJ, Aloorkar NH, Mali KK. Floating matrix tablet of atenolol: formulation and in-vitro evaluation. Asian journal of pharmaceutics 2009. p. 286-91.

21. Costa, P.,Lobo J. (2001). Modeling and comparison of dissolution profile.Eur J Pharma Sci., 13, 123-133.

22. Loew S, Fahr A, May S. Modeling the release kinetics of poorly water-soluble drug molecules from liposomal nanocarriers. J Drug Deliv. 2011. 